\title{
The Role of E-learning in Studying English as a Foreign Language in Saudi Arabia: Students' and Teachers' Perspectives
}

\author{
Ibrahim Mutambik ${ }^{1}$ \\ ${ }^{1}$ Information Science, King Saud University, Riyadh, Saudi Arabia \\ Correspondence: Ibrahim Mutambik, Information Science, King Saud University, Riyadh, Saudi Arabia. E-mail: \\ abrahim2005gxr@hotmail.com
}

Received: March 4, 2018 Accepted: April 14, 2018 Online Published: April 16, 2018

doi: 10.5539/elt.v11n5p74 URL: http://doi.org/10.5539/elt.v11n5p74

\begin{abstract}
Over the past few decades, there have been tremendous increase in technology advancement and the significance of this in the field of education cannot be overemphasised. The adoption and use of E-learning in studying EFL, in particular, is one such areas that has experienced such fast-paced development for some time now. As a result, the government all over the world are committing a lot of resources to keep up with this technology advancement. In this light, the government of Saudi Arabia through its Ministry of Education has recently made commitment, both as the practical and policy levels, with the hope to also benefit from using E-learning in studying EFL in Saudi Schools. However, little is known about the perception of students and teachers regarding the role of E-learning is studying EFL in the Saudi context. In an attempt to contribute to this research base, this paper draws on an empirical investigation using group interviews with students and teachers in order to gain insight into their perception about the role of E-learning in studying EFL in Saudi Arabia. The findings are presented and discussed in four thematic areas: promoting key learning skills, independent learning, flexible learning and interactive learning. The paper also highlights the limitations of the research and concludes by making a number of recommendations.
\end{abstract}

Keywords: E-learning, computer assisted language learning, English as a foreign language, students' and teachers' perspectives, qualitative analysis, Saudi Arabia

\section{Introduction}

\subsection{Introduce the Problem}

As information technology rapidly develops and spreads, there is an increasing body of literature that emphasizes the importance of introducing E-learning to facilitate the studying of English as a foreign/second language (EFL/ESL) depending on country or context (Yang \& Chen, 2007; Allam \& Elyas, 2016). This is particularly the case in Saudi Arabia in recent years (Al-Hamidi, 2013). The term E-learning, although a contested concept, is defined throughout this paper as computer-enabled learning of EFL. Today, this typically involves the use of the internet as a medium for teaching and learning, either as a principal or supplementary educational resource. There is also ample evidences regarding the relative potential benefits of this type of technology use, for both students and teachers. For example, it is suggested that E-learning offers the option to remove the temporal and spatial restrictions that apply in traditional learning contexts (Smith, 2000). In addition, some E-learning applications permit students learning English to readily access beneficial language resources and communicate directly with native English speakers. Furthermore, students can study English listening, verbal communication, reading, and written communication skills in authentic contexts (Debski \& Gruba, 1999; Yang \& Chen, 2007; Al-Qahtani, 2016; Al-Hassan \& Shukri, 2017).

However, Westbrook (2006) has argued that incorporating E-learning into the studying of EFL is not delivering anticipated outcomes. Debski and Gruba (1999) also suggested that while the successful inclusion of E-learning for the teaching and learning of EFL is measurable, proper assessment methods that capture the perceptions of both students and teachers towards technology use still demand consideration. Yet, the Saudi government, through the Ministry of Education is hoping to benefit from E-learning, and has progressively encouraged its implementation for studying EFL, particularly in high schools; i.e. ages 15 to 18 (Al-Hamidi, 2013). Thus, it seems there is a pressing need to explore the prevailing beliefs and opinions of both students and teachers relative to E-learning adoption for educational purposes. The significance of this paper lies in the fact that 
although numerous studies have been designed to comprehend the views of both students and teachers, regarding the successes and limitations of E-learning technology (Toni Mohr, Holtbrügge, \& Berg, 2012), there is a dearth of such relevant studies on this subject matter in the Saudi Arabian context. This paper reports the results of a qualitative research study designed to explore teachers' and students' perceptions regarding the introduction of E-learning into the domain of studying EFL in Saudi Arabia.

\subsection{Literature Review}

Computer based technological innovations have a long history in its use for the teaching and learning of EFL (Davies, 2012a, 2012b). In a broader sense, language education has utilised computer-based technologies since the 1960s, when educational researchers first showed an interest in using their capabilities in instruction following the development of commercial mainframe computers in the 1950s (Davies, 2012a). Over time, the popularity of technology adoption in the domain of education has increased, especially since the emergence of the World Wide Web.

A significant component of this technology advancement is the development of the E-learning environment which has been recognised as having transformative potential in terms of English language teaching and learning methodology (Hellebrandt, 1999). Specifically, students can use E-learning resources to acquire the four main English language skills (listening, speaking, reading, and writing) (Yang \& Chen, 2007; Shuchi, \& Islam, 2016). This section elaborates on the affordances of E-learning today, and discusses the implications for Saudi students, while also identifying the challenges associated with these aspects when balancing the argument.

One of the major limitations encountered with traditional face-to-face studying of EFL in Saudi Arabia is that students cannot be provided with an authentic English learning environment, as public life is primarily dominated by Arabic language. Furthermore, class sizes are very large, meaning there are limited opportunities for individual students to contribute or communicate one-to-one with their teachers. E-learning, therefore, offers a platform on which students can develop their communication (speaking) abilities in English by engaging with other students in the virtual-world (Yang \& Chen, 2007). It is worth noting that these limitations are not peculiar to the Saudi context but affects most other countries where English is used as a foreign language (Yang \& Chen, 2007).

In light of this, Lee (2002) conducted a pilot study using synchronous electronic chat together with task-based instructions, to enhance learners' communication skills. The outcome of that study suggested the combined use of online interaction and task-based instruction improves students' communication skills by creating a lively environment in which they can respond to conversations in real-time about topics relevant to their interests. Furthermore, Warschauer (1999) and Yang and Chen (2007) pointed out that the benefits of E-learning for developing speaking skills include the opportunity for more equal participation than supported during face-to-face interaction. In addition, that communication need not be confined to the local level, but can be easily and unprecedentedly extended to the international setting, opening up opportunities for learners to develop their cross-cultural knowledge (Al-saggaf, 2004). For example, teachers in Saudi Arabia can open up discussion groups for their students on any topic and invite participants from elsewhere to broaden and enrich the discussion, without the need to leave the country or physically mix in a sex-segregated environment. However, it is important to note here that, in Saudi Arabia, discussion platforms of this nature are considered more acceptable for university level students and less acceptable for use in relation to the school context (Madini \& de Nooy, 2014).

In terms of developing speaking skills, for those students who rarely have an opening to speak with native speakers, and for others who are shy, automatic speech recognition technology provides opportunities for them to practise speaking (Yang \& Chen, 2007). As noted by other researchers, including (Chiu, Liou, \& Yeh, 2007), the use of automatic speech recognition systems that allow students to engage in speech interactions with a computer is an advantage of E-learning. A web-based conversation environment called Candle Talk has also been developed to enable students to communicate with their computers interactively (Chiu et al., 2007). This software allows EFL learners to access explicit speech training programmes, thereby enhancing their oral skills. Additionally, the application of automatic speech recognition software as used by college freshmen can facilitate the teaching of oral communication. Importantly, the majority of students have welcomed instructional methods based on speech recognition software.

Another value addition of E-learning is that it is useful as a tool for creating successful learning environments to motivate students and create meaningful and worthwhile learning activities and outcomes (Garrison, 2011; Yang $\&$ Chen, 2007). For instance, Garrison (2011) has argued that the text-based E-learning communication, generated by e-mail messages or discussion threads, has unique and valuable attributes that can facilitate critical 
discourse and reflection.

Examining the significance of such text based tools, Al-Menei (2008) investigated the effectiveness of the computer-assisted English writing skills of Saudi students. His study demonstrated a significant improvement in the writing capabilities of Saudi EFL students when they had used computer-assisted programmes to correct their grammar and paragraph writing, as the E-learning setting provides ample time for students to reflect and focus. Farzi (2016) also observed that computers can be programmed to provide corrective instruction to identify any mistakes in writing. This arguably helps students to correct their mistakes, enriching their writing.

Furthermore, E-learning provide unprecedented opportunities when developing their reading skills, due to the unrestricted availability of course materials online (Brandl, 2002). Online information enables students to overcome the confines of textbook based learning, by promoting access to knowledge at any time and from anywhere. Opportunities for listening to authentic language also abound online. Indeed, Romeo (2008) observed the importance of listening exercises to understand relative clauses and audio prompts available through online applications. He reports on evidence that suggests that when more syntactically complex clauses are used, learners alter their method of approach to learning and understanding.

The E-learning interactions identified above do not only support the development of students' English language skills, but also foster students' interest and motivation in language learning in general. However, the benefits of an E-learning system cannot be maximized if students and teachers do not use it. The next section explains the methods used by the author to research the various benefits of E-learning mentioned above, from the perspective of teachers and students; while ensuring attention was also directed towards any disadvantages of E-learning that might emerge.

\section{Method}

To explore students' and teachers' perceptions of the role of E-learning in studying EFL in Saudi Arabia, a qualitative approach based on group interviews was used. Qualitative methods are well-established as in depth tools for exploring the perceptions of individuals and/or groups about particular phenomena including E-learning (Creswell, 2009). Therefore, this study employs a qualitative approach to gain insights into the meanings and interpretations the research participants ascribed to the role E-learning plays in studying EFL. Using a qualitative approach means participants' social reality can be conceived of as a constantly changing phenomenon with emergent properties (Bryman, 2004). Finally, understanding the construction of meaning was a central issue in this research and so the interview method assisted the researchers in learning how different individuals explain the role E-learning plays in studying EFL (Bogdan \& Biklen, 1982; Creswell, 2009).

Group interviews were used in this study and were preferred over other methods, because they allowed: rapid information gathering, cost-effective, the generation of new ideas, and raised issues and concerns that the researcher might not have encountered in individual interviews (Kumar, 1987; Ritchie \& Lewis, 2003). The study adopted a purposive sampling strategy and sought voluntary participation (Jupp, 2006; Mann \& Stewart, 2000). In total, 24 participants were selected from among the students and teachers since the aim was to achieve 'depth' rather than 'breadth' (Blaxter, Hughes, \& Tight, 2010; King \& Horrocks, 2010). The sample distribution included 16 students and 8 teachers.

The student participants were selected and grouped according to gender, English proficiency, and whether they had previous E-learning experience. Table 1 illustrates the distribution of the student participants. The decision to include these different criteria was made to ensure the selected sample was as diverse as possible within the defined population boundaries. According to Ritchie and Lewis (2003, p. 197) "diversity in group composition enriches the discussion, but there also needs to be some common ground between participants-based on how they relate to the research topic or their socio-demographic characteristics".

Table 1. Student participants according to proficiency, e-learning experience and gender

\begin{tabular}{ll}
\hline Participant category & Number of student participants (male - female) \\
\hline With E-learning experience \& High proficiency in English & $1-2$ \\
With E-learning experience \& Low proficiency in English & $3-2$ \\
Without E-learning experience \& High proficiency in English & $3-1$ \\
Without E-learning experience \& Low proficiency in English & $1-3$ \\
Total & $8-8$ \\
\hline
\end{tabular}


The teacher participants were divided according to gender and whether they had E-learning experience, as shown in Table 2 below.

Table 2. Teacher participants according to experience and gender

\begin{tabular}{ll}
\hline Participant category & Number of teacher participants (male - female) \\
\hline With E-learning experience & $2-2$ \\
Without E-learning experience & $2-2$ \\
Total & $4-4$ \\
\hline
\end{tabular}

In total there were four group interviews (lasting between 45 minutes and 1 hour). In total two groups of eight students and two groups of four teachers (males and females were interviewed separately in both cases, due to cultural and religious constraints on gender mixing). The rationale for involving both students and teachers (the primary users of E-learning in education) was to gain information about different experiences and ensure some diversity in the participants' characteristics. Collectively the sample size and distribution helped the authors to provide the diversity required to explore the topic and meet the aim of the study, as stated in the introduction.

The data collected during the group interviews was transcribed manually and then analysed thematically. This involved identifying, examining and interpreting themes in textual data and then asking how these themes helped address the research aim. The steps involved gaining familiarity with the data; generating initial codes; searching for themes; reviewing and naming themes; and conducting the analysis (Braun \& Clarke, 2006). The group analysis involved treating the data produced by the group as a whole, rather than focusing on individual contributions (Ritchie \& Lewis, 2003). Therefore, the groups were the units of analysis and were treated in the same way as units of individual data. Group analysis was used in this particular study, because it enabled the researchers to compare the differences and similarities between genders, as well as between teachers and students. The researcher chose thematic analysis as an analytical tool, because it was seen as an ongoing, fluid, and cyclical procedure occurring throughout the data collection stage, as well as involving data entry and analysis phases (Bryman, 2004).

Finally, ethical issues raised during the research were dealt with in the strictest confidentiality and data was anonymised in order to protect the identities of the respondents. The findings are presented below detailing the role of E-learning as perceived by each group.

\section{Findings and Discussion}

\subsection{The Role of E-learning in Promoting Key Learning Skills (Listening, Speaking, Reading, and Written)}

Despite the many benefits provided by E-learning in English education, the study participants in general focused on the development of listening and speaking skills only. As previously mentioned in the literature review, both skills are subject to considerable limitations in the context of traditional face-to-face English education in Saudi Arabia. The participants therefore saw E-learning as a platform, through which students would be able to develop their speaking and listening in real-world situations. For example, the male group shared some of their comments regarding the usefulness of E-learning, focusing on listening skills. Moreover, according to the M.S. group:

...Listening is one of the most important skills when learning English. You know, E-learning can provide audio and video to listen and watch as much as you can, which will improve students with weak listening skills and something like this e-learning should be used.

The above quotation illustrates a significant point associated with learning language; i.e. that E-learning can promote the development of students' listening skills. The respondents' position was also that E-learning could be instrumental in developing their listening skills more fully, particularly as they feel the current system is not student centred. The textbooks provided do not seek to develop all areas of students' skills, resulting in weaknesses in these areas. Resources in Saudi Arabia are also woefully inadequate, video-based activities are largely inappropriate, and little attempt is made to teach following a learner-centred methodology. This highlights the space for the usefulness of E-learning in a context such as Saudi Arabia. Another quotation considered interesting by the M.S. group is as follows:

There are many positive aspects I can think of, for example speaking, E-learning can maintain openness in communication that, if used in the right way, can be extended not only in the school community but all over the 
world. You know, speaking in English is one of the main skills, E-learning can support speaking skills when using chat rooms that are available in English. Since we are in a non-English speaking country, I see that E-learning will help to develop students' speaking skills.

This group also focused on highlighting speaking as a particular skill, considered useful in E-learning. They specifically felt that students might find chat rooms beneficial for practicing their speaking skills, providing opportunities currently unavailable in the traditional teaching and learning context. However they cautioned against total dependence on chat rooms for E-learning, because people might then feel isolated from one another and their teachers. The outcome of this research supports research on communication by Warschauer (1996) who argues that, “... the benefits of communication are seen as many: feeling part of a community, developing thoughts and ideas, learning about different people and cultures, and students' learning from each other" (p. 39). In this research the respondents identified development in their speaking skills as a core affordance of E-learning.

On the other hand, E-learning was also perceived as potentially inhibiting some aspects of English learning. For example, the F.T. group stated:

..., it should not affect the other skills that students acquire from face-to-face teaching and learning, such as handwriting skills...

Thus, a need for moderation emerged when interpreting this groups' perceptions of the usefulness of E-learning. That is, while the participants recognised the usefulness of E-learning (implicitly); they cautioned against potential negative impacts, such as students not developing handwriting appropriately.

Overall, the analyses showed that E-learning helps to develop students' listening and speaking skills, which is important as proficiency in these areas is lacking in individuals who receive a traditional face-to-face English education in Saudi Arabia only. This is because, as mentioned above, Saudi Arabia does not offer the opportunity for students to be exposed to a natural English learning environment, as Arabic languages dominate public life.

Interestingly, the groups were relatively silent on the other benefits of E-learning for promoting reading and writing skills. Possibly, this is because these areas are already well provided for by traditional methods of teaching and learning. However, research reported elsewhere asserts that mastery of reading and writing in English can be supported through E-learning (Al-Menei, 2008; Brandl, 2002).

What was also clear from the responses of the teachers and students was that they spoke generally about E-learning and the use of technology, but did not elaborate on how it can be applied to the development of learning EFL. This means that both teachers and students emphasised the technology itself, rather than how this facilitates studying EFL. The reason for this could be that E-learning is a new development in Saudi Arabia, especially at the school level, and the research respondents may have lacked the awareness or knowledge of its utilities. This research outcome concurs with findings reported by Yang and Chen (2007), who also found that the majority of students who research technology-enhanced language learning, appear to place greater emphasis on the technology than on the language learning. What also appears to be missing is recognition of the fact that speaking and listening helps forge relationships (Purdy, 1997). This research outcome therefore calls for a need to develop teacher training in this area.

\subsection{The Role of E-learning in Promoting Independent Learning}

During the interviews, the potential for E-learning to foster independent learning came to the fore as a key advantage. For instance, one F.T. suggested that:

I think if it is implemented in the right way, this will reduce the effort I do in the school, and this [E-learning] helps students to rely on themselves and have different learning styles of English.

The above quotation from this teacher highlights the possibility that applying E-learning provides different learning styles. Kinsella (1995) defines 'styles' more generally as: "being an individual's natural, habitual, and preferred way of absorbing, processing, and retaining new information and skills" (p. 171). Christison (2003) also acknowledges the numerous ways of characterising learning styles, including: cognitive style, sensory style, and personality styles. The identification of learning styles is however particularly useful when understood relative to the needs of this research, because as argued in the work of Oxford (2002), "when allowed to learn in their favourite way, unpressured by learning environment or other factors, students often use strategies that directly reflect their preferred learning" (p. 127). One F.S. also made a useful comment in this regard, as follows:

The one thing that stimulates me to use E-learning is the huge amount of information that is easily accessible on it. 
The above statement suggests that through E-learning a lot of information can be made readily available to students to enable learning regardless of context. Students do not have to be in the classroom to access relevant information, nor do they always require the presence of a teacher. This was the characteristic of technology that respondents considered very user friendly. However, another student who had never used E-learning had the following to say:

You know, I don't have any experience with E-learning, you know, I don't think it will be easy for me to use it.

This student was clearly concerned that it would not be easy to use E-learning without any experience and limited guidance. This highlights the importance of the teacher's role in supporting students when using E-learning tools.

Moreover, the F.S. group commented that E-learning promotes independent learning by providing feedback. For example they mentioned:

... E-learning sometimes gives feedback immediately, which is sometimes helpful, especially when you don't need a teacher to know if your answer is correct or not. ..., this really encourages us...

This suggests that students consider it motivating that they can use E-learning technology to learn independently without their teachers watching or intruding. As stated, a key aspect of this is the opportunity to access instant feedback when using E-learning. Indeed, the capacity for computers to provide instant and individualised feedback has long been recognised by educators as beneficial to the learning process, including foreign language educators (Salaberry, 2001; Alrabai, 2017). Additionally, findings from research by Ghanizadeh, Razavi and Jahedizadeh (2015), demonstrate that modern technologies improve the quality of input, the authenticity of communication, and the relevance of feedback. All of the above corroborates the position of the F.S. group.

\subsection{The Role of E-learning in Promoting Flexible Learning}

Many of the participants stated that the flexibility that E-learning offers can promote English learning. For example, according to one of the F.T group:

Through [E-learning] students have access to the coursework 24 hours/day which gives them more flexibility on time to follow up what they missed in the classroom and I think that will help to improve their English.

This statement contends that students who are willing and able to practice more, will take the opportunities offered by E-learning tools and thereby effectively improve their English. Emphasis should therefore be placed on the flexibility provided by the chance to practice any time, rather than just the mere availability of the resources online. In relation to flexibility of place, the respondents stated:

... They can have access to coursework from schools or home or where ever they have a computer and internet connection. Teachers also can have the same flexibility to monitor students' progress.

The concept of flexibility mentioned above, extends beyond students to include teachers. What this means is that with E-learning, both students and teachers can perform their duties from anywhere. A similar viewpoint was raised in the other groups. For instance, the F.S group mentioned:

We can use it [E-learning] any time which means we have flexibility to use E-learning to complete more exercises or to do homework.

The male group also provided insight into how they consider E-learning to be flexible to meet their teaching and learning needs. Quoting the M.S. group:

Most of students spend time on the internet, you know; in the traditional classroom I have limited time to learn but with the use of E-learning I will have unlimited access to the lessons for learning in my free time. In our learning of English nowadays, we are restricted in learning only in the classroom, which means we don't have flexibility. I think E-learning will help us to overcome all geographical and spatial barriers for students to learn English and exchange knowledge.

The above comment goes a step further than previous comments made by the participants, observing that E-learning removes geographical and spatial barriers for students. This points to the fact that utilising E-learning resources, students from more than one geographical setting can communicate easily. This functionality can then motivate students to engage with others irrespective of geography, which can then influence them to use the interactive affordances of E-learning.

Additionally, this feature could broaden students' horizons both socially and culturally, through their interactions with the outside world and when reading for pleasure. According to Yang and Chen (2007), Internet technology has a global reach and can provide extensive international resources. Similarly, E-learning enables English 
students to access useful language learning resources and communicate directly with native English speakers. In the former, students are able to practice the application of information, while in the latter case, they can overcome the decontextualized nature of English language learning. Students can also learn listening, speaking, reading and writing English in an integrated form via E-learning. Finally, E-learning offers students the opportunity to broaden their international perspectives, and appreciate different cultures.

\subsection{The Role of E-learning in Promoting Interactive Learning}

The participants indicated that E-learning is an interactive tool allowing very effective communication between students or with their teachers. For instance, one teacher mentioned that E-learning can provide a means of communication between teachers and students outside the classroom, enabling them to augment everyday learning and teaching of English. The F.T. mentioned:

..., the E-learning environments is different to traditional learning because E-learning can be a complete set of technology tools, which allow teachers and students to interact in a new style via the internet outside the classroom, to support daily learning and teaching of English...

The above comment suggests that learning and teaching in English using E-learning can help develop an interactive relationship among the students themselves and between teachers and students. This could play an essential role in bolstering students learning English. This opinion was then echoed by other teachers in the same group, who also perceived E-learning as an interactive teaching tool. The views of the F.S. group on this subject are captured below:

Our educational system now, it doesn't support interaction with students who come from different regions, while we in the school come from the same area, I think E-learning will help me to interact somehow with other students, even from different countries to practice my language.

The implication here is that as a result of the interactive component of E-learning students from different countries can learn from one another. This was also suggested by Shumin (2002) who argued that, "because of the lack of opportunity in foreign language settings to interact with native speakers, the need for exposure to many kinds of scenes, situations, and accents as well as voices is particularly critical" (p. 209). The view expressed here is in many ways similar to the research outcome by Yang and Chen (2007), discussed above in the section concerning The role of E-learning in promoting flexible learning. Students appear to have a more global perspective on English language learning. Indeed, some students in the F.S. group mentioned:

I will then use it [E-learning], because it will add something new to learning English, which interaction with other students or teacher is more open, I meant, I can interact outside the school.

The male gender group also suggested a similar view:

..., the online interaction aspect that E-learning will provide to students and teachers is one of the most important advantages of E-learning, such as, marking, sending and receiving the homework. I think in this way, E-learning will increase the possibility of contact between students and teachers, this may include email, discussion boards and chat rooms. So, the students will have more time to participate and interact when learning English outside the classroom.

The above two comments suggested that although they considered interactivity between teachers and students as something important when learning English, they identified that E-learning facilitates this better outside the classroom setting. For instance, in an E-learning environment, it seems essential to facilitate students' and teachers' proactive involvement for English learning and teaching through various forms of interaction, including online collaboration and the provision of instant feedback. Thus, effective collaboration between teachers and students are key to an effective teaching and learning process, both online and offline; a position that echoes existing research, highlighting the importance of a collaborative approach to E-learning. This is facilitated through increased contact between student-student and/or student-teacher. This conclusion is supported by findings in Chen's (2014) study, which found that, "the nature of interactivity and immediate feedback of a WBEL environment has a positive effect on the stimulation of students' interest and proficiency in English learning" (p. 160). This research outcome demonstrates that knowledge is constructed as a result of constant negotiation between students and teachers. It also emphasises the belief that learning is a social communication process.

\section{Conclusions}

This paper aimed to explore the perception of students and teachers about the role of E-learning in studying EFL in Saudi Arabia. The research outcome has been quiet revealing in a number of ways. In particular, special 
prominence was given to E-learning benefits in relation to individuals' speaking and listening skills. It was suggested by both students and teachers that using E-learning in studying EFL in Saudi Arabia provides opportunities for the development of students speaking and listening skills which might be lacking in the current curriculum. Although this was perceived to be a good thing, it was also observed that it might come at a cost of other skills, such as writing, reading and grammar, neither teachers nor students raised these skills. E-learning also allows learners to communicate with different people worldwide via chatrooms in a relatively easier, flexible and interactive manner. These key attributes (e.g. flexibility and interactivity) and consequences (e.g. usefulness) of using E-learning when applied for learning EFL in Saudi Arabia might result in successful implementation of such technology. Furthermore, special prominence was given to how E-learning promotes independent learning with less intrusion from their teachers.

However, it seems that both students and teachers were focusing more on the attributes of E-learning rather than how it develops their use of EFL and how it can be integrated into the Saudi curriculum in order to augment results. In the current study, it is also noticeable that comparing the views of students and teachers demonstrated that the former seemed more informed than the later about such technology. The implication is that teachers might lack the requisite knowledge to bring together the two pedagogies (traditional and E-learning). This suggests a clear need to offer training to teachers regarding how to apply such technology to the educational curriculum. The study therefore prescribes Hampel and Stickler (2005) seminal series of skills, ranging from technological to pedagogical, that teachers could be encouraged to acquire for effective teaching using E-learning. This is supported by Hung (2016), who contended that for users to use E-learning effectively they require skills, such as the ability to identify resources for learning, selecting and implementing learning strategies, monitoring personal performance, and effectively applying skills and knowledge to reach learning objectives. More importantly, Lai, Yeung, and $\mathrm{Hu}$ (2016) have argued that teachers need to share strategies with their students about how to comprehend authentic materials and learn from them. They contend that doing so will help guide students to develop the skills and strategies they require to process authentic materials.

Herein, the research outcomes establish the importance of setting realistic E-learning systems to meet students' and teachers' expectations and to promote learning EFL in Saudi Arabia. Such a system is necessary in order to develop key English learning skills (i.e. reading, writing, speaking and listening) in an easy, interactive and fixable ways. The system should also be able to facilitate independent learning. In conclusion, this research is limited in a number of ways. For instance, with a small sample size means that caution must be applied in its application, as findings might not be transferable to a large population. The study was also conducted in Saudi Arabia, which is heavily influenced by social norms, meaning the views reported in the study might be both culture and context dependent.

\section{References}

Al-Hamidi, M. (2013, November 13). Teaching English in Saudi Arabia from paper into E-learning. Asharq Al-Awsat. Retrieved from http://aawsat.com/home/article/8730

Al-Hassan, S., \& Shukri, N. (2017). The Effect of Blended Learning in Enhancing Female Students' Satisfaction in the Saudi Context. English Language Teaching, 10(6), 190. https://doi.org/10.5539/elt.v10n6p190

Al-Qahtani, A. A. (2016). Do Saudi EFL Teachers Promote Creativity in Their Classrooms?. English Language Teaching, 9(4), 11. https://doi.org/10.5539/elt.v9n4p11

Al-Menei, A. (2008). An Investigation of the Effect of Computer-assisted Writing Instruction on EFL Saudi Learners' Ability. King Saud University. Retrieved from http://repository.ksu.edu.sa/jspui/bitstream/123456789/19275/1/Thesis by Ahmed M. O. Al-Menei.pdf

Al-saggaf, Y. (2004). The Effect of Online Community on Offline Community in Saudi Arabia. The Electronic Journal on Information Systems in Developing Countries, 16(2), 1-16. https://doi.org/10.1002/j.1681-4835.2004.tb00103.x

Allam, M., \& Elyas, T. (2016). Perceptions of Using Social Media as an ELT Tool among EFL Teachers within the Saudi Context. English Language Teaching, 9(7), 1. https://doi.org/10.5539/elt.v9n7p1

Alrabai, F. (2017). Exploring the Unknown: The Autonomy of Saudi EFL Learners. English Language Teaching, 10(5), 222-233. https://doi.org/10.5539/elt.v10n5p222

Blaxter, L., Hughes, C., \& Tight, M. (2010). How to research (4th ed). Maidenhead: Open University Press.

Bogdan, R., \& Biklen, S. K. (1982). Qualitative research for education: an introduction to theory and methods. London: Allyn and Bacon. 
Brandl, K. (2002). Integrating Internet-based reading materials into the foreign language curriculum: from teacher-to-student-centered approaches. Language Learning \& Technology, 6(3), 87-107.

Braun, V., \& Clarke, V. (2006). Using thematic analysis in psychology. Qualitative Research in Psychology, 3(2), 77-101. https://doi.org/10.1191/1478088706qp063oa

Bryman, A. (2004). Social Research Methods (2nd ed). Oxford: Oxford University Press.

Chiu, T.-L., Liou, H.-C., \& Yeh, Y. (2007). A Study of web-based oral activities enhanced by Automatic Speech Recognition for EFL college learning. Computer Assisted Language Learning, 20(3), 209-233. https://doi.org/10.1080/09588220701489374

Creswell, J. W. (2009). Research design: qualitative, quantitative, and mixed methods approaches. Los Angeles, Calif: Sage.

Davies, G. (2012a). Computer Assisted Language Learning: Where are we now and where are we going? Retrieved June 21, 2016, from http://www.camsoftpartners.co.uk/docs/UCALL_Keynote.htm

Davies, G. (2012b). Lessons from the past, lessons for the future: 20 years of CALL. Retrieved June 21, 2016, from http://www.camsoftpartners.co.uk/coegdd1.htm

Debski, R., \& Gruba, P. (1999). A Qualitative Survey of Tertiary Instructor Attitudes towards Project-BasedCALL. Computer Assisted Language Learning, 12(3), 219-239. https://doi.org/10.1076/call.12.3.219.5715

Farzi, R. (2016). Taming Translation Technology for L2 Writing: Documenting the Use of Free Online Translation Tools by ESL Students in a Writing Course. University of Ottawa. University of Ottawa.

Garrison, D. R. (2011). E-Learning in the 21st Century. New York: Routledge. http://doi.org/10.4324/9780203838761

Hampel, R., \& Stickler, U. (2005). New skills for new classrooms: Training tutors to teach languages online. Computer Assisted Language Learning, 18(4), 311-326. https://doi.org/10.1080/09588220500335455

Hellebrandt, J. (1999). Virtual Collaborations in The Spanish Class: From E-Mail To Web Design and Cd-Rom Development. Journal of Educational Computing Research, 20(1), 59-70. https://doi.org/10.2190/6BQA-UHYL-4JJK-V1R4

Hung, M.-L. (2016). Teacher readiness for online learning: Scale development and teacher perceptions. Computers \& Education, 94, 120-133. https://doi.org/10.1016/j.compedu.2015.11.012

Jupp, V. (2006). The Sage Dictionary of Social Research Methods. London: Sage Publications Ltd. https://doi.org/10.4135/9780857020116

King, N., \& Horrocks, C. (2010). Interviews in Qualitative Research. Los Angeles: Sage.

Kinsella, K. (1995). Understanding and empowering diverse learners in the ESL classroom. In J. Reid (Ed.), Learning styles in the ESL/EFL classroom (pp. 70-194). Boston, MA: Heinle \& Heinle.

Kumar, K. (1987). Conducting group interviews in developing countries. Washington: US Agency for International Development. Retrieved from http://pdf.usaid.gov/pdf_docs/PNAAL088.pdf

Lai, C., Yeung, Y., \& Hu, J. (2016). University student and teacher perceptions of teacher roles in promoting autonomous language learning with technology outside the classroom. Computer Assisted Language Learning, 29(4), 703-723. https://doi.org/10.1080/09588221.2015.1016441

Lee, L. (2002). Enhancing Learners' Communication Skills through Synchronous Electronic Interaction and Task-Based Instruction. Foreign Language Annals, $35(1), \quad$ 16-24. https://doi.org/10.1111/j.1944-9720.2002.tb01829.x

Madini, A. A., \& de Nooy, J. (2014). Cross-gender communication in a Saudi Arabian Internet discussion forum: Opportunities, attitudes, and reactions. Convergence: The International Journal of Research into New Media Technologies, 22(1), 54-70. https://doi.org/10.1177/1354856514534574

Mann, C., \& Stewart, F. (2000). Internet communication and qualitative research: A handbook for researching online. London: Sage Publications Ltd. https://doi.org/10.4135/9781849209281

Shuchi, I. J., \& Islam, A. B. M. (2016). Teachers' and Students' Attitudes towards L1 Use in EFL Classrooms in the Contexts of Bangladesh and Saudi Arabia. English Language Teaching, 9(12), 62-73. https://doi.org/10.5539/elt.v9n12p62 
Oxford, R. L. (2002). Language Learning Strategies in a Nutshell: Update and ESL Suggestions. In J. C. Richards, \& W. A. Renandya (Eds.), Methodology in Language Teaching (pp. 124-132). Cambridge: Cambridge University Press. https://doi.org/10.1017/CBO9780511667190.018

\section{Copyrights}

Copyright for this article is retained by the author(s), with first publication rights granted to the journal.

This is an open-access article distributed under the terms and conditions of the Creative Commons Attribution license (http://creativecommons.org/licenses/by/4.0/). 